\title{
Oxygen-generating photocrosslinkable hydrogels support cardiac progenitor cell survival by reducing hypoxia-induced necrosis
}

Neslihan Alemdar, Jeroen Leijten, Gulden Camci-Unal, Jesper Hjortnaes, Joao Ribas, Arghya Paul, Pooria Mostafalu, Akhilesh K. Gaharwar, Yiling Qiu, Sameer Sonkusale, Ronglih Liao, Ali Khademhosseini

Supporting Information:

Supplemental figures: 2

Supplemental pages: 3 


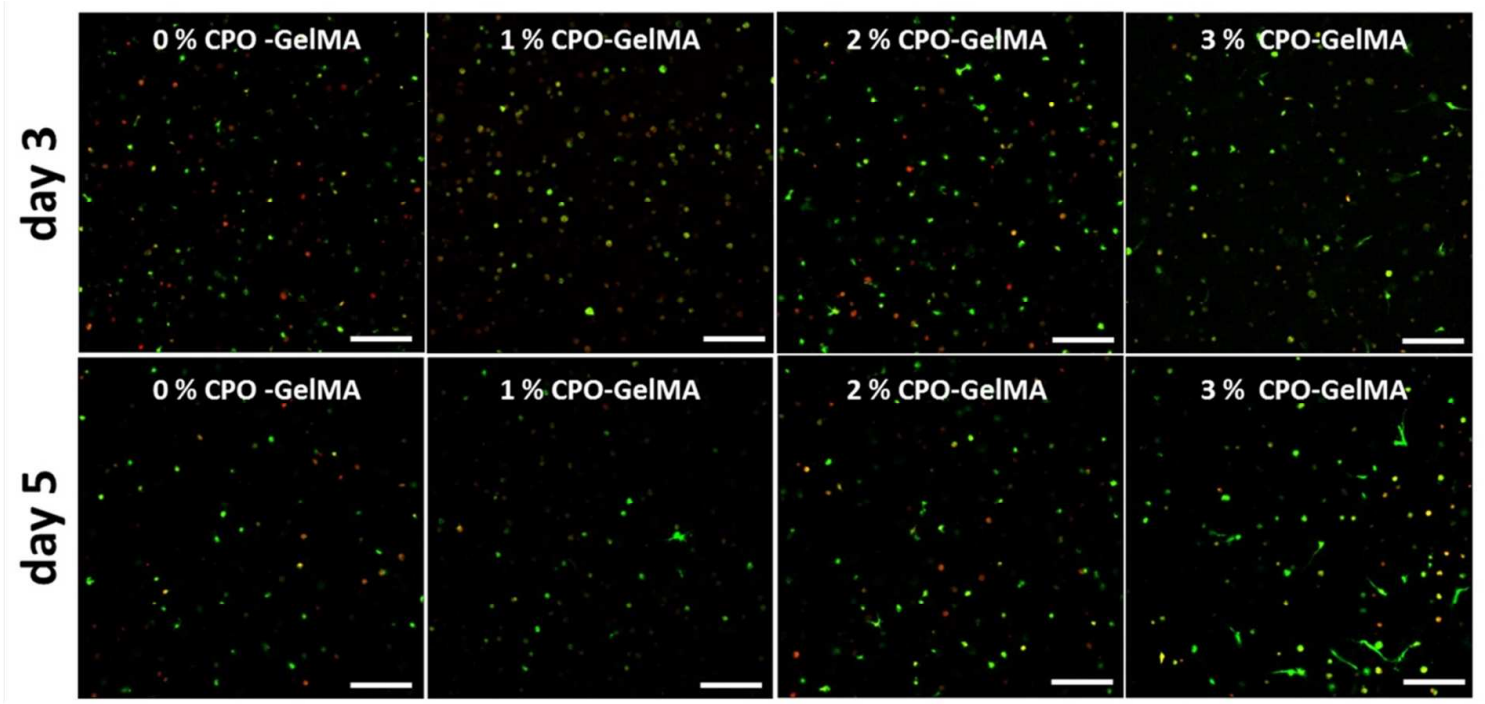

Figure S1: Confocal microphotographs of live/dead stained CSPs cultured in CPO-GelMA containing 0, $1,2,3 \%$ CPO under hypoxic conditions for three or five days. Live or dead cells are stained green or red, respectively. Scale bar equals 50 micrometer. 

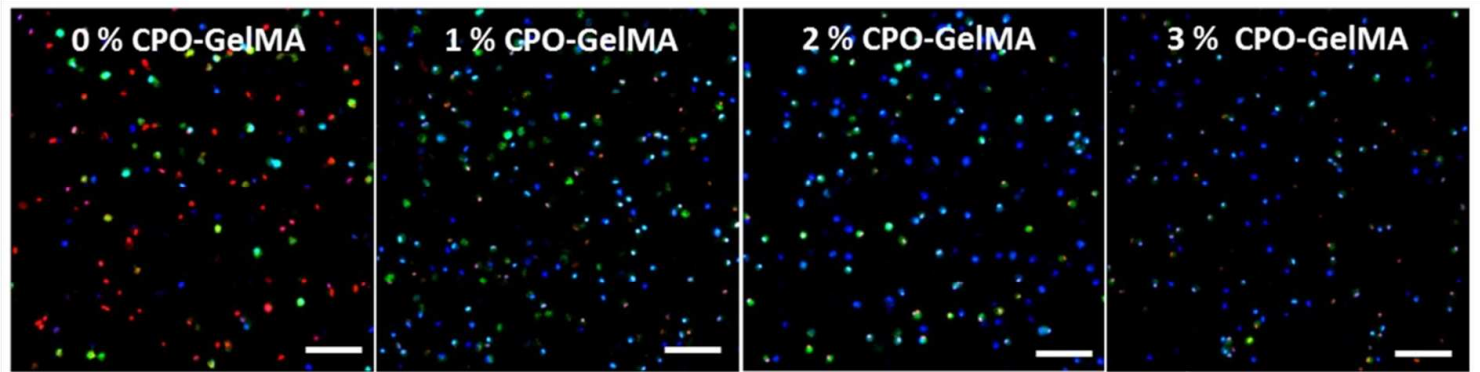

Figure S2: Confocal microphotographs of healthy, apoptotic, and necrotic CSPs cultured in CPOGelMA containing $0,1,2,3 \%$ CPO under hypoxic conditions. Healthy, apoptotic, and necrotic cells stained blue, green and red, respectively. Scale bar equals 50 micrometer. 